\title{
A Dilated Pore of Winer with Four Openings
}

\author{
Ru-Zhi Zhang ${ }^{1}$ and Wen-Yuan Zhu, ${ }^{*}$ \\ ${ }^{I}$ Department of Dermatology, Third Affiliated Hospital of Suzhou University, 185 Juqian Road, Changzhou, 213003, \\ China \\ ${ }^{2}$ Department of Dermatology, the First Affiliated Hospital of Nanjing Medical University, Nanjing 210029, China
}

\begin{abstract}
Dilated pore was originally designated as a secondary or acquired trichoepithelioma by Winer, represents an appendageal tumor with differentiation towards hair structures. It is clinically characterized by having the appearance of a large blackhead filled with keratinous material. To the best of our knowledge, there has been no report of a dilated pore with four openings. We herein describe such a case.
\end{abstract}

Keywords: Dilated pore, nodule.

\section{INTRODUCTION}

Dilated pore was described by Winer [1] in 1954 as an enlarged solitary pore filled with a plug of keratin seen predominately on the face of adult men. It has the histologic appearance of a large cystic cavity, which is filled with basket weave cornified debris that simulates the normal stratum corneum although it may be thickened and more compact. We report an unusual dilated pore of Winer with four openings.

\section{CASE REPORT}

A 68-year-old man presented with a 35-year-history of asymptomatic, gradually increasing nodule with four heads on the left chest. The patient did not have a past history of severe acne and denied any preceding trauma or scratch on this site. He had no concomitant dermatological diseases, thyroid dysfunction or any other autoimmune disease. He had no inherited disorders or nevus malformations, nor did any members of his family. Historically, the patient could remove some caseous, white, soggy keratin from the lesion, but the pores were refilled with keratotic materials within several weeks.

On clinical examination, the lesion was a $1.5 \times 1.6 \mathrm{~cm}$, elastic-firm, comedo-like lesion with four black keratinous plugs in the center (Fig. 1). The curatively excisional specimen histologically showed a flask-shaped, cystic structure in the dermis filled with basket weave cornified debris (Fig. 2). The epithelial lining of the structure connecting to the surface epidermis was atrophic near the surface. Based on the clinical manifestation and pathological findings, the diagnosis of a dilated pore of Winer was made. To the best of our knowledge, a dilated pore characterized as four openings with keratotic plugs in one nodule has not been described previously in the literature.

*Address correspondence to this author at the Department of Dermatology, the First Affiliated Hospital of Nanjing Medical University, Nanjing 210029, China; Tel: 18761161826; E-mail: zhuwenyuan@yahoo.com

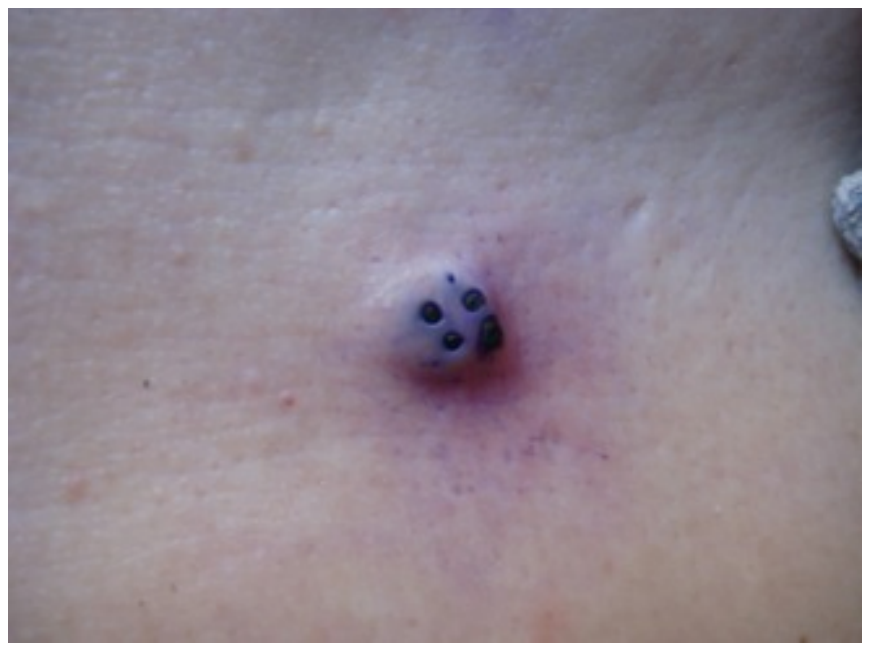

Fig. (1). Clinical presentation: four black keratinous plugs in the center of a nodule.

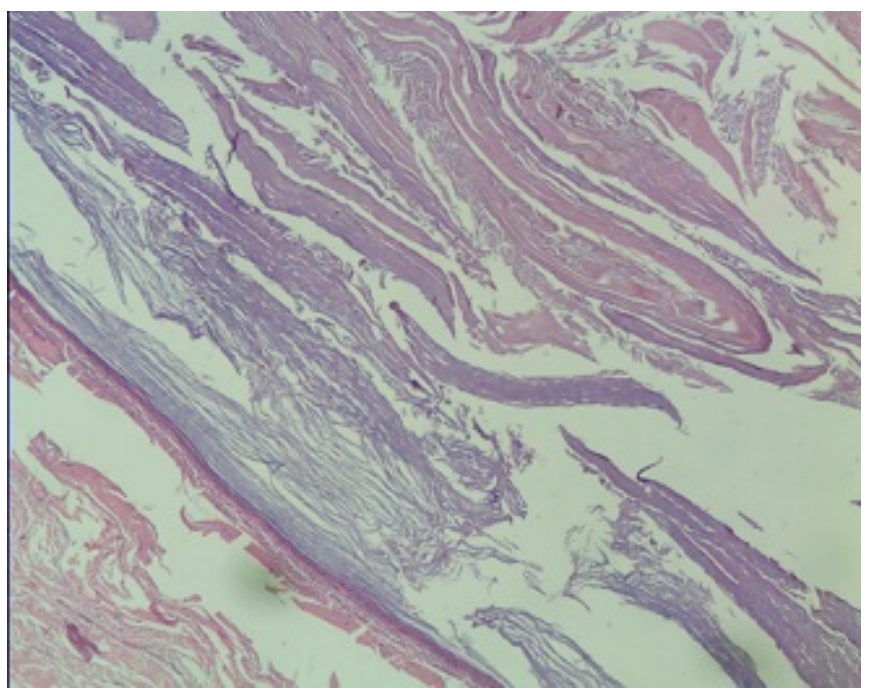

Fig. (2). Histological examination: a flask-shaped, cystic structure in the dermis filled with basket weave cornified debris. $(\mathrm{HE} \times 40)$. 


\section{DISCUSSION}

Dilated pore represents an appendageal tumor with differentiation towards hair structures and was originally designated as a secondary or acquired trichoepithelioma by Winer [1]. It has the appearance of a giant comedo. More commonly, chronic manipulation and expression may lead to inflammation and infection of the surrounding tissue. Histologic examination of a biopsy specimen from the lesion is the only way to make a definitive diagnosis. No medical treatment is available for a dilated pore of Winer. Excision of the entire lesion is curative. Prognosis of dilated pore is excellent. Rare lesions may be associated with trichoblastoma [2] and exceptionally with either basal cell carcinoma [3] or squamous cell carcinoma [4].

In our patient, the lesion was a nodule with four enlarged pores filled with plug of keratin. Clinical presentation and pathological finding supported the diagnosis of dilated pore. Because of its unusual appearance, the differential diagnoses should include epidermoid cyst [5], aggregated giant comedones [6], nevus comedonicus [7], dilated pore nevus [8] and aggregated dilated pores [9]. A typical epidermoid cyst looks like a raised and round bump. It can move around under the skin fairly easily if you touch it [5]. Often there is a small opening on the surface, but that opening is so small that it is difficult to see, it may look like a scab. Aggregated giant comedones frequently occur on actinically damaged facial skin of predisposed middle-aged and elderly people, with typical distribution lateral to the eye in an individual with prominent signs of actinic damage, especially elastotic changes [6]. Nevus comedonicus (also known as a "Comedo nevus") is congenital or childhood linear keratinous cystic invaginations of the epidermis, present with closely arranged, grouped, often linear, slightly elevated papules that have at their center keratinous plugs [7]. If comedo nevus associated with cataracts, scoliosis, and neurologic abnormalitie, nevus comedonicus syndrome is considered [10].

Dilated pore naevus is clinically indistinguishable from comedo nevus [8]. These cysts individually are indistinguishable from the dilated pore of Winer. However, a dilated pore nevus has also been described with onset in adulthood. Aggregated dilated pores were reported by Konohana et al. as multiple comedone- like lesions appearing since adulthood with each lesion displaying the histologic features of dilated pore [9]. Clinically, our case is similar to the aggregated dilated pores, but not identical to that. The lesion in our patient may originate from a same follicular, but developed at different parts of the hair follicle, but it was confirmed by pathological examination, regrettably we did not provide a photo of lower magnification to show entire architecture of the lesion. We believe that our report may contribute to the study of dilated pore and other comedo-like lesions.

\section{CONFLICT OF INTEREST}

The authors confirm that this article content has no conflict of interest.

\section{ACKNOWLEDGEMENTS}

Declared none.

\section{REFERENCES}

[1] Winer LH. The dilated pore, a tricho-epithelioma. J Invest Dermatol 1954; 23: 181-8

[2] Misago N, Sada A, Narisawa Y. Trichoblastoma with a dilated pore. J Am Acad Dermatol 2006; 54: 357-8.

[3] Carlson-Sweet KL, Weigand DA, MacFarlane DF. Trichoid basal cell carcinoma found in a dilated pore on the nose. Dermatol Surg 2000; 26: 874-6.

[4] Zhao L, Xu J, Fang F, Qian G, Wang Y, Wang QQ. Squamous cell carcinoma found in a dilated pore. J Eur Acad Dermatol Venereol 2007; 21: 277-8.

[5] Skroza N, Proietti I, Tolino E, et al. Isotretinoin for the treatment of squamous cell carcinoma arising on an epidermoid cyst. Dermatol Ther 2014; 27: 94-6.

[6] Agius JRG. Grouped periorbital comedones. Br J Dermaol 1964; 76: $158-64$

[7] Bhagwat PV, Tophakhane RS, Rathod RM, Tonita NM, Naidu V. Nevus comedonicus along Blaschko's lines. Indian J Dermatol Venereol Leprol 2009; 75: 330.

[8] Resnik KS, Kantor GR, Howe NR, Ditre CM. Dilated pore nevus. A histologic variant of nevus comedonicus. Am J Dermatopathol 1993; 15: 169-71.

[9] Konohana A, Kobayashi T. Aggregated dilated pores. J Dermatol 1999; 26: 332-3.

[10] Pavithra S, Pai H, Mallya H, Pai GS. Nevus comedonicus syndrome. Indian J Dermatol 2011; 56: 771-2. 